Article

\title{
Effects of Red Mud Addition in the Microstructure, Durability and Mechanical Performance of Cement Mortars
}

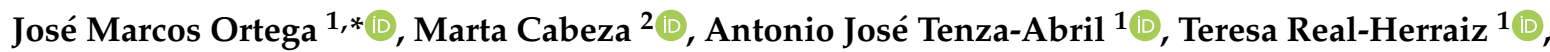 \\ Miguel Ángel Climent ${ }^{1}$ (D) and Isidro Sánchez ${ }^{1}$ (D) \\ 1 Departamento de Ingeniería Civil, Universidad de Alicante, Ap. Correos 99, 03080 Alacant/Alicante, Spain; \\ ajt.abril@ua.es (A.J.T.-A.); teresa.real@ua.es (T.R.-H.); ma.climent@ua.es (M.Á.C.); isidro.sanchez@ua.es (I.S.) \\ 2 Grupo ENCOMAT, Escola de Enxeñaría Industrial, Universidade de Vigo, Campus universitario, 36310 Vigo, \\ Spain; mcabeza@uvigo.es \\ * Correspondence: jm.ortega@ua.es; Tel.: +34-96-5903-400 (ext. 2470)
}

Received: 31 December 2018; Accepted: 1 March 2019; Published: 8 March 2019

\begin{abstract}
Recently, there has been a great effort to incorporate industrial waste into cement-based materials to reach a more sustainable cement industry. In this regard, the Bayer process of obtaining alumina from bauxite generates huge amounts of waste called red mud. Few research articles have pointed out the possibility that red mud has pozzolanic activity. In view of that, the objective of this research is to analyse the short-term effects in the pore structure, mechanical performance and durability of mortars which incorporate up to $20 \%$ of red mud as a clinker replacement. As a reference, ordinary Portland cement and fly ash Portland cement mortars were also studied. The microstructure was characterised through mercury intrusion porosimetry and non-destructive impedance spectroscopy, which has not previously been used for studying the pore network evolution of red mud cement-based materials. The possible pozzolanic activity of red mud has been checked using differential scanning calorimetry. The non-steady state chloride migration coefficient and the mechanical properties were studied too. According to the results obtained, the addition of red mud entailed a greater microstructure refinement of the mortar, did not worsen the resistance against chloride ingress and reduced the compressive strength compared to control binders.
\end{abstract}

Keywords: sustainability; red mud; microstructure; durability; chloride ingress resistance; mechanical properties; impedance spectroscopy

\section{Introduction}

Nowadays, recycling and reusing waste is an important challenge for achieving a more sustainable environment. Between the different wastes produced by industrial processes, it is important to highlight red mud, which is a residue generated by the digestion of bauxite minerals with caustic soda during the production of alumina through the Bayer process. For every tonne of alumina extracted, approximately 1.6 tons of red mud are produced and it is estimated that more than 66 million tons of this waste are generated annually worldwide [1,2].

This high amount constitutes a serious environmental problem, especially in areas where this industry is implanted. In addition to this, it also has a relatively high economic cost (between $1 \%$ and $2 \%$ of the price of the alumina), because red mud residues must be stored in rafts which require a large amount of space (it is estimated that there is a surface of $1 \mathrm{~km}^{2}$ of rafts every five years for a plant which produces one million tons of alumina per year) [3]. Furthermore, the removal of red mud by direct discharge into the sea is also highly polluting, since the toxic metals present in this waste can be dispersed over long distances. Red mud is generally presented as sludge with a concentration of solids 
between $10 \%$ and $30 \%$, and with a highly alkaline $\mathrm{pH}$. In the last few decades, several investigations have been performed about the possible reuse of red mud in various fields. Among the different studies, it is interesting to highlight those focused on its use in the treatment of water and soil [4,5], its use as a catalyst [6] and its application in construction and structural materials [7-10].

The construction sector is a major contaminant industrial sector [11], so the lessening of its $\mathrm{CO}_{2}$ emissions is now a relevant issue of study. One way to reduce those emissions is by substituting clinker with additions [12-14] and the majority of them are pollutant residues originated from other industrial processes, such as fly ash, ground granulated blast-furnace slag and silica fume [15-20]. In relation to the use of red mud in cement-based materials, considering its composition, it is possible that it has pozzolanic activity and some research has pointed out this possibility [21,22]. Along this line, there are several dispersed works related to the use of this addition in those materials and some of them have shown that red mud seems to improve protection against corrosion of reinforcements embedded in concrete [23-26], as well as the transport properties of cement-based materials [27]. In addition to this, there are also some recent studies in which the mechanical strengths of cementitious materials with red mud have been analysed. Some examples are self-compacting concretes [28,29], geopolymers [30] and lightweight concretes [31].

Regarding the presence of hazardous elements in red mud, there are several studies in which it has been shown that the presence of red mud is not dangerous for the users of structures or works made with construction materials with this addition. One of these studies was developed by Krivenko et al. [10]. In that work, the healthy safe application of red mud in different mixtures was tested, studying the radiological properties of their constituents and their resulting construction materials. These authors [10] concluded that from a radiological point of view, all materials with red mud studied in their research were safe, and they are able to be used. In addition to this, they pointed out that even a red mud incorporation of $90 \%$ by mass would be safe for the particular application of road construction [10]. In another study, developed by Manfroi et al. [22], an environmental assessment of cement-based materials with red mud was also performed. These authors [22] pointed out that mortars with $5 \%$ and $10 \%$ of red mud would be safe, despite of releasing more heavy metals than mortar without red mud, and those mortars with red mud even showed lower concentrations of cadmium compared to the reference mortar. In view of that, these authors suggested that the hydration products of cement-based materials with red mud could contribute to a fixation of contaminants and they would be especially good for retention of cadmium contaminants.

The durability and mechanical performance of cement-based materials is directly related to their microstructure [32-34], so the analysis of the changes in the pore network of the abovementioned materials is interesting. However, there have been few studies examining the microstructure of cementitious materials with red mud [21,22]. Among the different techniques for analysing the changes in the pore network of those materials, nowadays non-destructive techniques are a relevant field of research. One of these techniques is the relatively novel impedance spectroscopy, which is being increasingly used. This technique has recently been applied for cement-based materials which incorporate different kinds of additions. Some of these additions are well-known and widely used, such as slag and fly ash [35], and others are relatively new, like waste brick powder [36] and glass powder [37]. Impedance spectroscopy has also been successfully used for studying how aggressive and non-optimum environments $[14,38]$ affect the evolution of the microstructure of cement pastes, mortars and concretes. Nevertheless, it has only been used for studying the development of the corrosion phenomenon of steel bars inreinforced concrete with red mud [26] and there is no experience related to the use of impedance spectroscopy for following the changes in the microstructure of mortars with this addition.

Thus, the main objective of this work is to analyse the short-term effects of the addition of red mud in the microstructure, mechanical properties and durability of mortars which incorporate several percentages of this addition (up to $20 \%$ ) as a clinker replacement. In order to have a reference, mortars made with Portland cement with fly ash (a more conventional and widely used addition) and mortars 
made using ordinary Portland cement without additions were also studied. The well-known mercury intrusion porosimetry and the non-destructive impedance spectroscopy technique were used for characterising the pore network of the specimens. Moreover, differential scanning calorimetry was performed for checking the possible pozzolanic activity of the red mud. Regarding the durability, the non-steady state chloride migration coefficient was determined. Finally, in order to assess the effects of the red mud addition in the mechanical behaviour of the mortars, compressive and flexural strengths were also studied.

\section{Experimental Setup}

\subsection{Sample Preparation and Curing}

In this work, six types of cement mortars have been analysed. On one hand, mortars made with a commercial ordinary Portland cement, designated CEM I 42.5 R (CEM I hereafter), according to the Spanish and European standard UNE-EN 197-1 [39], were prepared. On the other hand, mortars prepared with a commercial Portland cement with fly ash, CEM II/B-V 42.5 R [39] (CEM II from now on), which has a fly ash content from $21 \%$ to $35 \%$ (by weight), were also studied.

In addition to this, mortars with different contents of red mud were tested. Those mortars were prepared with ordinary Portland cement, CEM I 42.5 R [39], which was partially replaced by 5\%, $10 \%, 15 \%$ and $20 \%$ of red mud. They have been named as RM5, RM10, RM15 and RM20 respectively hereafter. After drying, the ground red mud was passed through a sieve of $125 \mu \mathrm{m}$ and more than $60 \%$ of the material also passed through asieve of $63 \mu \mathrm{m}$. The red mud was provided by the company Alcoa, from its factory at San Cibrao, Spain, and its chemical composition can be observed in Table 1.

Table 1. Chemical composition of red mud (weight basis) [40].

\begin{tabular}{cc}
\hline Composition & Red Mud \\
\hline $\mathrm{SiO}_{2}$ & $9 \%$ \\
$\mathrm{Al}_{2} \mathrm{O}_{3}$ & $12 \%$ \\
$\mathrm{CaO}$ & $6 \%$ \\
$\mathrm{Fe}_{2} \mathrm{O}_{3}$ & $37 \%$ \\
$\mathrm{Na}_{2} \mathrm{O}$ & $5 \%$ \\
$\mathrm{TiO}_{2}$ & $20 \%$ \\
$\mathrm{H}_{2} \mathrm{O}\left(100{ }^{\circ} \mathrm{C}\right)$ & $11 \%$ \\
\hline
\end{tabular}

All the specimens were prepared with a water to binder ratio of 0.5 and with an aggregate to cement ratio of 3:1. The particle size distribution of the aggregate used is shown in Table 2. Both kinds of samples (cylindrical and prismatic) were made. The dimensions of the cylindrical specimens were $15 \mathrm{~cm}$ height and $10 \mathrm{~cm}$ diameter, whereas the prismatic samples had measurements of $4 \mathrm{~cm} \times 4 \mathrm{~cm} \times$ $16 \mathrm{~cm}$ [41]. Once set, both kinds of specimens were maintained in a chamber at $20^{\circ} \mathrm{C}$ and $95 \%$ relative humidity (RH) for the first $24 \mathrm{~h}$. After that time, the samples were de-moulded and the cylindrical ones were cut to obtain slices of $1 \mathrm{~cm}$ and $5 \mathrm{~cm}$ height. Lastly, all the specimens were kept under optimum hardening conditions $\left(20^{\circ} \mathrm{C}\right.$ and $\left.100 \% \mathrm{RH}\right)$ until the testing ages.

Table 2. Particle size distribution of the aggregate used.

\begin{tabular}{cc}
\hline Sieve (mm) & Cummulative Passing \\
\hline 4 & $100 \%$ \\
2 & $99.97 \%$ \\
1 & $67.69 \%$ \\
0.5 & $33.23 \%$ \\
0.25 & $23.08 \%$ \\
0.125 & $2.26 \%$ \\
0.063 & $0.23 \%$ \\
\hline
\end{tabular}




\subsection{Mercury Intrusion Porosimetry}

The pore structure of the specimens was studied using the well-known mercury intrusion porosimetry technique, in spite of its main drawbacks [42,43]. The porosimeter used was a model Autopore IV 9500 manufactured by Micromeritics Instrument Corp. (Norcross, GA, USA). Before the test, samples were dried in an oven at $50{ }^{\circ} \mathrm{C}$ for $48 \mathrm{~h}$. The analysed parameters were total porosity, pore size distribution and percentage of $\mathrm{Hg}$ retained at the end of the test. The hardening ages studied were $7,28,45,75$ and 90 days. Due to the toxic and pollutant characteristics of the mercury, as well as the complex management of the contaminated samples after testing, only two measurements were made for each binder and age.

\subsection{Differential Scanning Calorimetry}

Differential scanning calorimetry determinations were made on samples to study the evolution of the amount of portlandite present in the materials. The calorimeter used was a Mettler-Toledo DSC822 (Columbus, $\mathrm{OH}, \mathrm{USA}$ ) at a heating rate of $10{ }^{\circ} \mathrm{C} / \mathrm{min}$. The temperature range scanned was from $25^{\circ} \mathrm{C}$ to $650{ }^{\circ} \mathrm{C}$ and the heat transmitted per gram of sample was measured. The heat liberated in the peak corresponding to the decomposition of portlandite was analysed for the mortars with the lowest and the highest content of red mud (RM5 and RM20 respectively), as well as for the CEM I and CEM II specimens, at the hardening times of $10,28,45$ and 75 days.

\subsection{Impedance Spectroscopy}

The changes in the pore network of the mortars have also been followed with the non-destructive impedance spectroscopy technique. It has several advantages compared to other classical techniques, such as the ability to get global data of the microstructure of the samples [44,45]. Recently, several works have been published $[14,38,46]$ where this non-destructive and global technique has been used for analysing the evolution of the pore structure of different cement-based materials (pastes, mortars and concretes) with additions, obtaining very good results. Some of these additions are well-known and widely used, such as slag and fly ash [35], and others are relatively new, like waste brick powder [36] and glass powder [37]. Impedance spectroscopy has also been successfully used for studying how aggressive and non-optimum environments $[14,38]$ affect the evolution of the microstructure of cement pastes, mortars and concretes. However, there is scarce knowledge about applying this technique for studying cementitious materials that incorporate red mud to replace clinker [26], although, in view of the previously mentioned successful studies, impedance spectroscopy could be suitable for following the microstructure evolution of materials with red mud.

The measurements were performed using an impedance analyser Agilent 4294A manufactured by Agilent Technologies (Kobe, Japan), which permits capacitance measurements in the range from $10^{-14} \mathrm{~F}$ to $0.1 \mathrm{~F}$, having a highest resolution of $10^{-15} \mathrm{~F}$. In this study, the interval of frequencies for getting the impedance spectra was between $100 \mathrm{~Hz}$ and $100 \mathrm{MHz}$. The electrodes used for measuring had a circular shape $(8 \mathrm{~cm}$ diameter) and they consisted of a copper piece with the same diameter to which a flexible graphite sheet was attached. For performing the measurements, contacting and non-contacting methods were used [44]. In Figure 1, the experimental setup of the impedance measurement of a mortar sample using the contacting method is shown. The impedance spectra, after Kramers-Krönig validation [47], were fitted to the two time constants equivalent circuits established by Cabeza et al. [44] (see Figure 2). These circuits are formed by resistances and capacitances, which give data related to different characteristics of the microstructure of cement-based materials. 


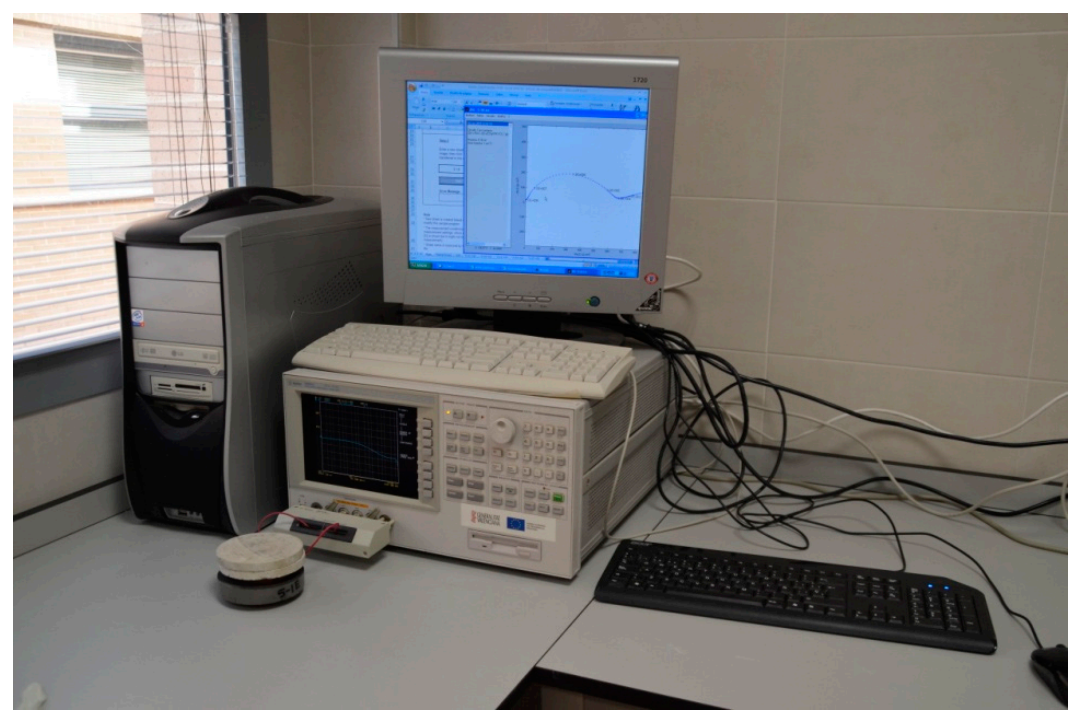

Figure 1. Experimental setup of the impedance measurement of a mortar sample using the contacting method.
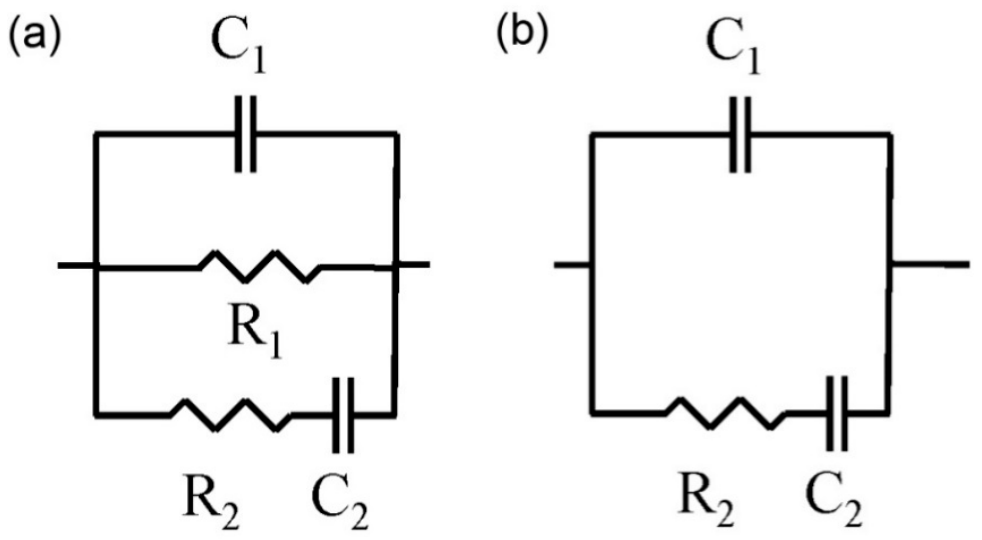

Figure 2. (a) Equivalent circuit used for the fitting of the impedance spectra obtained using the contacting method. (b) Equivalent circuit used for the fitting of the impedance spectra obtained using the non-contacting method. $\mathrm{R}=$ resistance; $\mathrm{C}=$ capacitance.

In this study, only the resistance $R_{1}$ and the capacitance $C_{2}$ were analysed. The impedance resistance $R_{1}$ provides data associated with the percolating pores of the specimen and the capacitance $\mathrm{C}_{2}$ provides data about the pore surface in contact with the electrolyte which fills the pore structure of the sample. The impedance parameter $\mathrm{C}_{2}$ is present in the equivalent circuits of both contacting and non-contacting methods (see Figure 2), and in this research, only its values obtained with the non-contacting method have been analysed, due to its better accuracy.

The evolution of the resistance $R_{1}$ and the capacitance $C_{2}$ was studied for the mortars with the lowest and the highest content of red mud (RM5 and RM20 respectively), as well as for CEM I and CEM II specimens at the hardening ages of 10, 28, 45 and 75 days. Four different disks of $1 \mathrm{~cm}$ thickness were tested for each one of the abovementioned binders.

\subsection{Forced Migration Test}

The chloride migration test was performed on water-saturated mortar samples, following the NT Build 492 standard [48]. The non-steady-state chloride migration coefficient $\mathrm{D}_{\mathrm{NTB}}$ was the result of this test. For each binder, at 7, 28, 45, 75 and 90 days, three different cylindrical specimens of $5 \mathrm{~cm}$ height and $10 \mathrm{~cm}$ diameter were tested. 


\subsection{Mechanical Strength Test}

The flexural and compressive strengths were determined according to the Spanish and European standard UNE-EN 196-1 [41]. In order to check the average effects on the mechanical behaviour of the addition of red mud, the abovementioned strengths were only studied in the RM10 and RM15 specimens, which were compared to those obtained for CEM I and CEM II samples. The test was performed at 7, 28, 45, 75 and 90 days. At those ages, three different $4 \mathrm{~cm} \times 4 \mathrm{~cm} \times 16 \mathrm{~cm}$ samples were trialled for each one of the previously mentioned binders.

\section{Results and Discussion}

\subsection{Mercury Intrusion Porosimetry}

The total porosity results for CEM I, CEM II, RM5, RM10, RM15 and RM20 mortars can be observed in Figure 3. At seven days of age, RM10 and RM15 mortars showed lower total porosities compared to CEM I and CEM II. On the other hand, at that hardening age, this porosity is higher for the RM5 and RM20 specimens than for mortars prepared with CEM I and CEM II. The total porosity of the RM5 samples decreased with time, whereas it kept approximately constant for the rest of the mortars with different contents of red mud. After 90 hardening days, all the studied mortars showed similar values of total porosity, with the exception of RM20 specimens, whose porosity was between $2 \%$ and $3 \%$ higher.

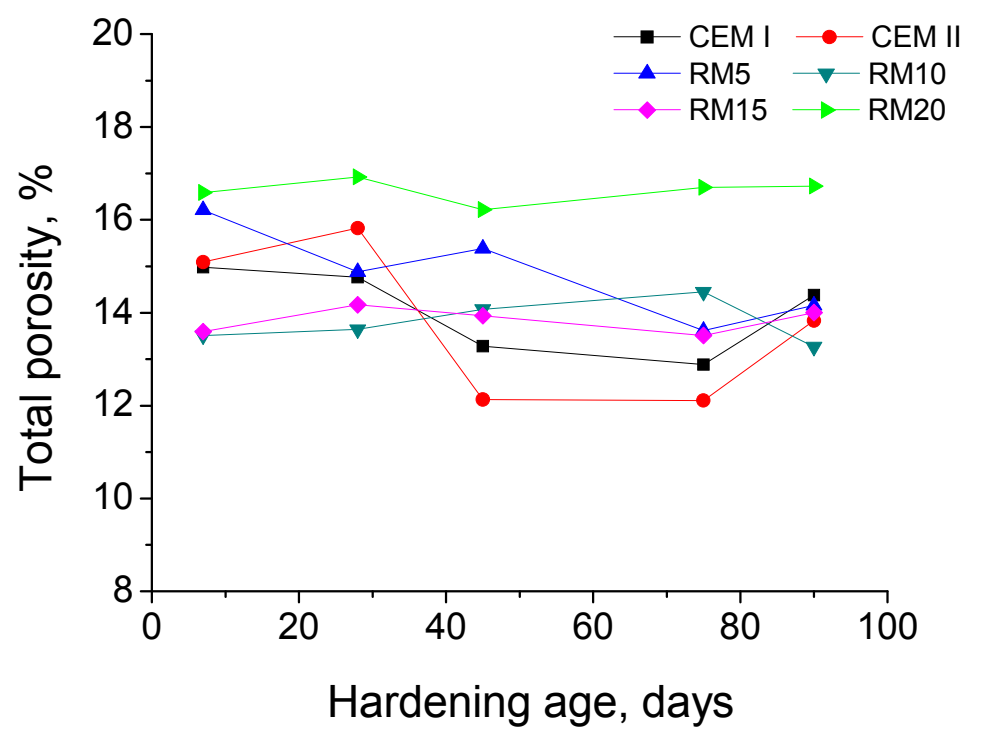

Figure 3. Results of total porosity for mortars prepared with contents of 5\% (RM5), 10\% (RM10), $15 \%$ (RM15) and 20\% (RM20) of red mud, compared to those obtained for ordinary Portland cement (CEM I) and Portland cement with fly ash (CEM II) mortars.

The pore size distributions obtained for the studied samples are shown in Figures 4 and 5. As can be observed in both figures, the pore network of the mortars with red mud addition is more refined than those obtained for CEM I and CEM II samples, which suggests the result that the red mud samples generally showed higher volumes of pores with diameters lower than $100 \mathrm{~nm}$ (addition of volumes of ranges $<10 \mathrm{~nm}$ and $10-100 \mathrm{~nm}$ ), compared to CEM I and CEM II specimens. In addition to this, it is important to note the relatively high volume of pores with sizes included in the ranges $<10 \mathrm{~nm}$ and 10-100 nm observed for mortars with red mud, which increased with hardening time. Furthermore, the microstructure of the mortars became more refined with increases in red mud content. These results could be related to the possible pozzolanic activity of the red mud [21,22], or due to the fact that the fine particles of red mud may act as filler [22,23], occupying part of the existing pores and producing a reduction of the pore sections. On the other hand, a slight increase in the volume of the 
largest pore range has been observed in binders RM5 and RM20 compared to the reference mortars. Finally, the fluctuation of the intrusion volume for CEM I and CEM II samples at 45 days and 75 days could be due to a more efficient compacting of the samples.

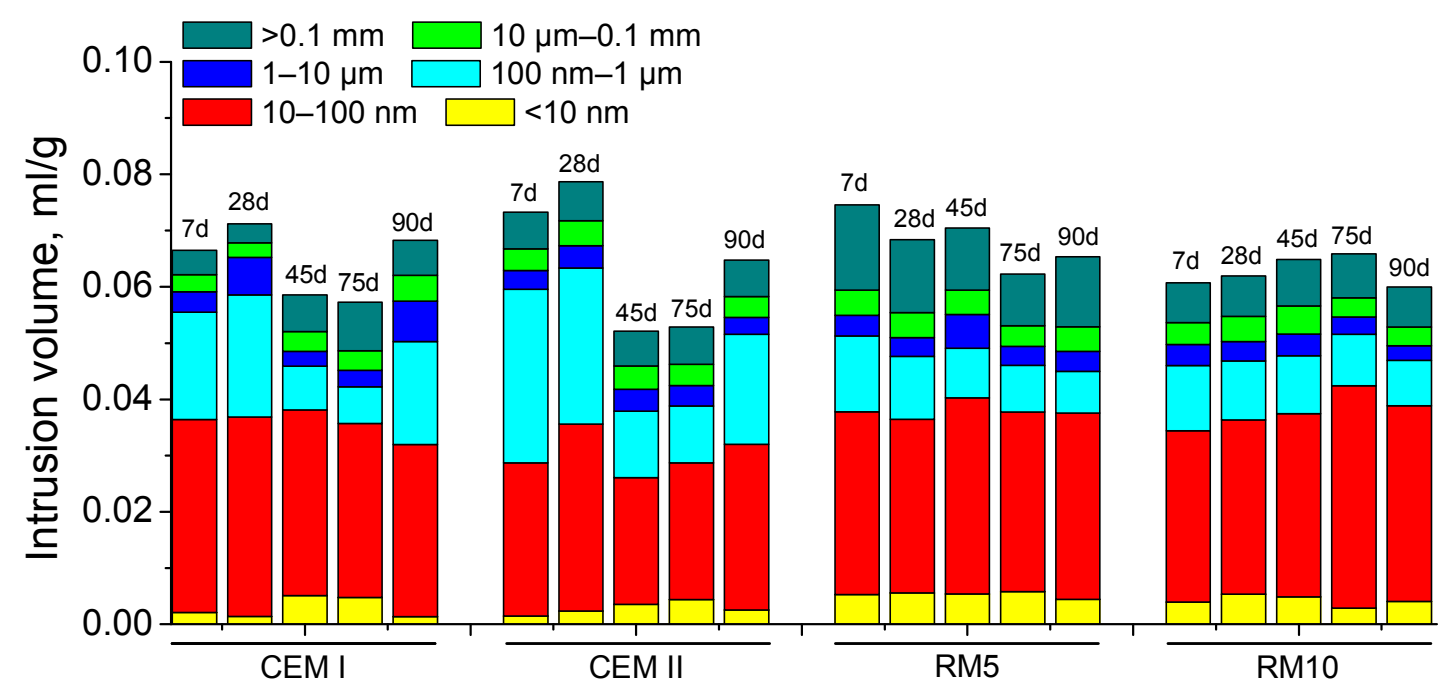

Figure 4. Pore size distributions obtained for CEM I, CEM II, RM5 and RM10 mortars.

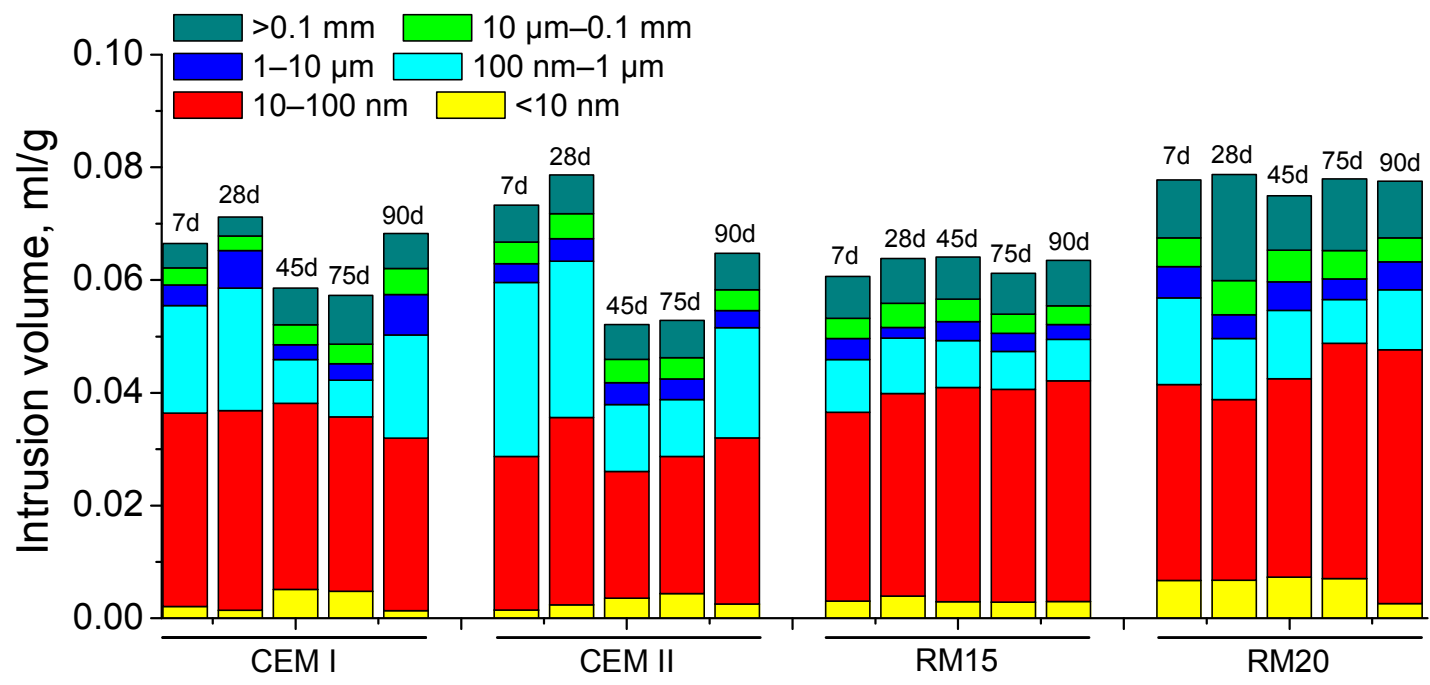

Figure 5. Pore size distributions noted for mortars with 15\% (RM15) and 20\% (RM20) red mud content. Pore size distributions of CEM I and CEM II mortars have also been included in order to facilitate the comparison between the abovementioned red mud mortars and those made using commercial cements.

The percentages of mercury retained in the studied samples after testing are shown in Figure 6. At early hardening ages, the red mud mortars showed greater percentages of $\mathrm{Hg}$ retained compared to CEM I and CEM II specimens. This would suggest that the addition of red mud would entail an increase of the tortuosity of the pore network of the mortars. However, at 90 days, the $\mathrm{Hg}$ retained values were very similar for all the tested mortars, although it was slightly higher for those with a $5 \%$ red mud content. 


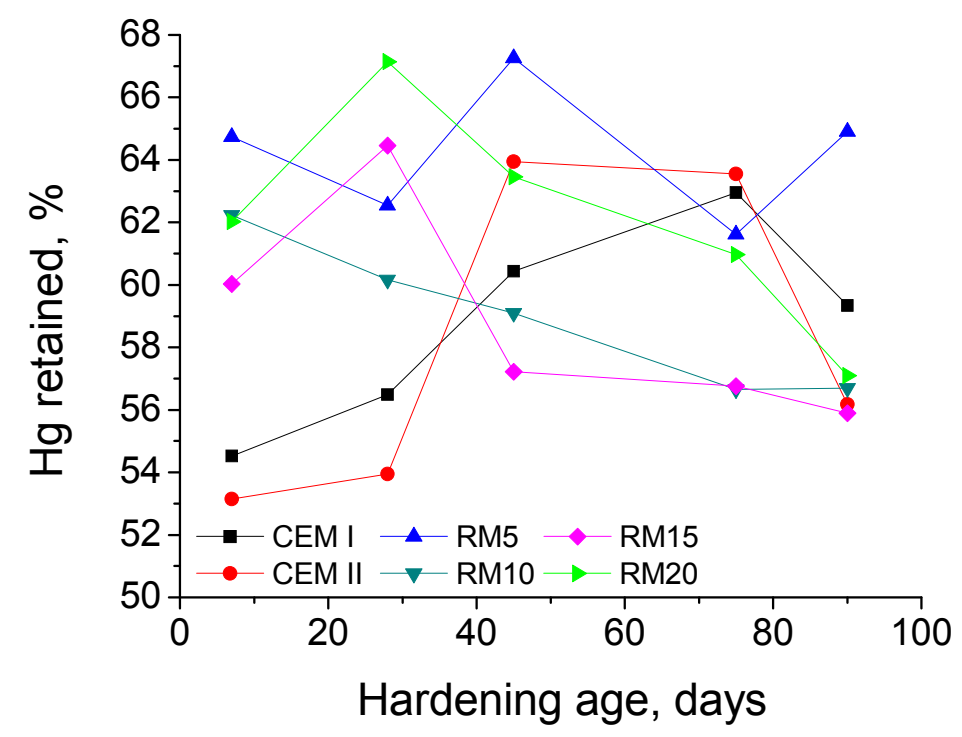

Figure 6. Evolution of $\mathrm{Hg}$ retained once porosimetry testing was completed for the studied mortars.

In view of the mercury intrusion porosimetry results, it could be pointed out that the use of red mud as a cement addition produces an improvement of the pore network of the mortars, especially in relation to its higher refinement. The presence of a high volume of pores with small diameters in red mud mortars could be interpreted as being due to the pozzolanic activity of these muds [21,22]. This would mean that the particles of red mud could be capable of reacting with the clinker hydration products, forming calcium silicate hydrate (CSH) phases [22,27], which would progressively fill the pores and produce a more compact microstructure.

Finally, the fact that it has not been noted a fall of total porosity from seven days to 90 days for mortars with $20 \%$ of red mud, being its values the highest of all the studied samples, could be due to the relative great content of red mud of these mortars. As a consequence of this greater percentage of red mud, a higher hardening time could be expected in order to note noticeable effects of red mud pozzolanic reactions in total porosity [22,27], as suggested by the abovementioned obtained results.

\subsection{Differential Scanning Calorimetry}

To check the possible reactivity of the red mud, differential scanning calorimetry measurements were made. This is a commonly used technique to study the pozzolanic activity of some new materials [49]. For that purpose, the mortars with the lowest and the highest content of red mud (RM5 and RM20 respectively) were tested, as well as the CEM I and CEM II mortars, which were taken as a reference for comparison. In this work, the heat per gram of sample released in the decomposition of the portlandite was studied, whose results for the abovementioned mortars are shown in Figure 7. As it can be observed, the heat for the cements with red mud is the lowest at every age, and it decreases with time.

This evolution of the portlandite peak and the decreasing amount of heat released for samples prepared with red mud would indicate the presence of less portlandite. This could be produced by the possible pozzolanic reaction of the red mud with the portlandite formed in the clinker hydration, according to other studies [22,27]. The possibility of carbonation was rejected, because samples did not present carbonation, which was checked using the phenolphthalein test. Following this, the results of the differential scanning calorimetry corroborated the pozzolanic activity of the red mud. In addition to this, they would be in line with the mercury intrusion porosimetry tests discussed previously. 


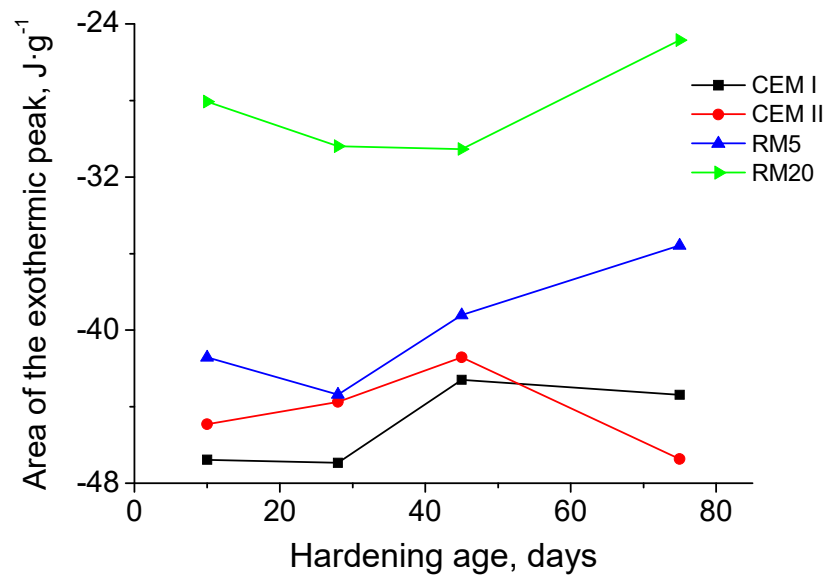

Figure 7. Evolution with hardening time of the heat liberated in the peak corresponding to the decomposition of portlandite.

\subsection{Impedance Spectroscopy}

The results of resistance $R_{1}$ and capacitance $C_{2}$ are depicted in Figures 8 and 9, respectively. As it has already been discussed in previous works [44,50], the resistance $R_{1}$ is related to the amount and diameter of the percolating pores of the specimen and the $C_{2}$ capacitance is proportional to the surface of its pores (solid-electrolyte contact surface). Therefore, with these parameters, it is possible to study the evolution of the potential pozzolanic reactions of the red mud, as performed in several works for cement-based materials which incorporate other additions, such as fly ash [51], brick powder [36] and glass powder [37]. In order to obtain information about the pozzolanic activity of red mud, only the mortars with the lowest and the highest percentages of red mud (RM5 and RM20) were analysed using impedance spectroscopy. Their results were compared to CEM I and CEM II mortars.

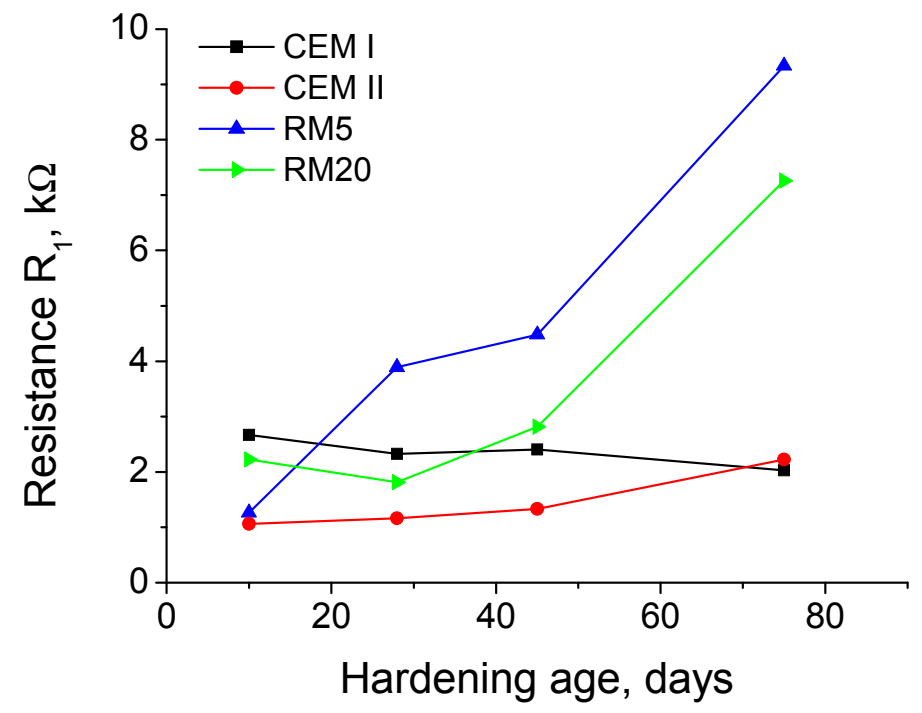

Figure 8. Results of impedance spectroscopy resistance $\mathrm{R}_{1}$ for CEM I, CEM II, RM5 and RM20 mortars. 


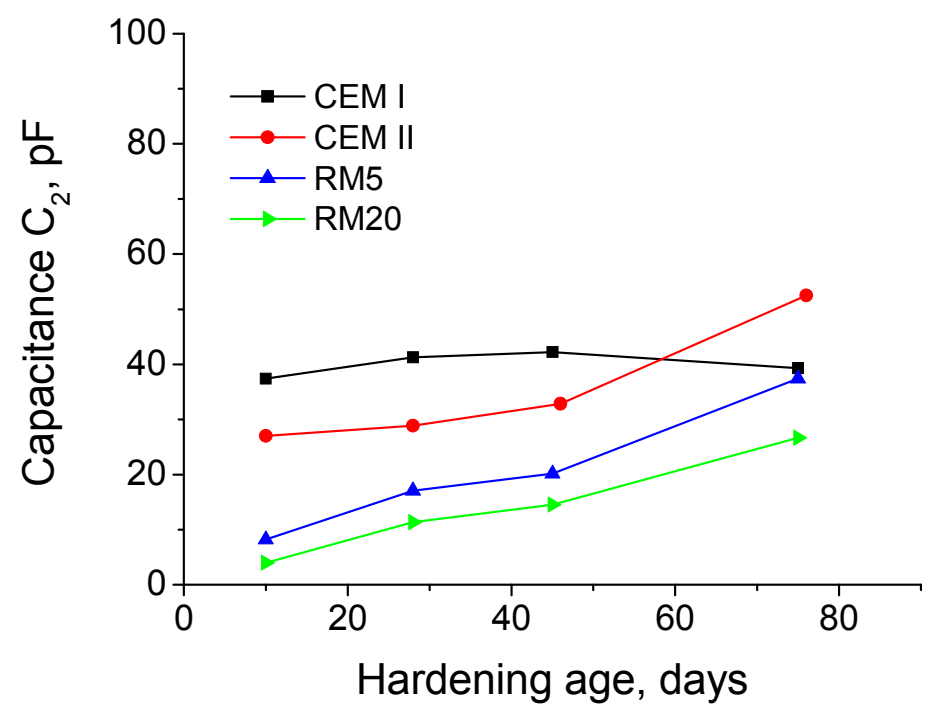

Figure 9. Results of impedance spectroscopy capacitance $C_{2}$ for CEM I, CEM II, RM5 and RM20 mortars.

Regarding the resistance $\mathrm{R}_{1}$ (see Figure 8 ), this parameter remained practically constant for CEM I specimens, while it increased with time for the mortars with red mud and fly ash. Nonetheless, the rising rate of this resistance was greater for the samples with red mud, and as a consequence, the $R_{1}$ values were higher for those mortars in comparison with CEM I and CEM II, mainly from 45 hardening days. The rise of the $\mathrm{R}_{1}$ with age and its higher values noted for the red mud mortars would agree with the mercury intrusion porosimetry results, especially with their important pore refinement noted, which has been explained in relation to the development of pozzolanic reactions of this addition $[22,27]$.

In relation to the evolution of capacitance $C_{2}$ (see Figure 9), this parameter hardly changed with time for CEM I samples, and it rose for the rest of studied mortars. These results are consistent with those noted for resistance $\mathrm{R}_{1}$, already described and discussed. The increase of capacitance would also mean the formation of new solids, which would consist of new cementing phases such as CSH gels, produced due to the development of fly ash [52,53] and red mud pozzolanic reactions [22,27]. These new solid phases would form rough structures on the existing surface of the pores, increasing the solid-electrolyte interphase, and as a consequence the $C_{2}$ values, which would justify the results of this parameter noted for red mud and fly ash mortars. This interpretation is also in line with the progressive increase with time of the proportion of smaller pores (microstructure refinement) showed by mercury intrusion porosimetry for these types of analysed mortars.

\subsection{Forced Migration Test}

In order to assess the influence of the addition of red mud in the durability of the mortars, the non-steady-state chloride migration coefficient $\mathrm{D}_{\mathrm{NTB}}$ has been determined. The changes with time of this parameter for the analysed mortars can be observed in Figure 10.

The mortars with red mud showed similar or even lower chloride migration coefficients overall than those observed for CEM I and CEM II specimens at the majority of studied ages. At seven hardening days, the coefficient $\mathrm{D}_{\mathrm{NTB}}$ was higher for CEM II and RM5 mortars than for the rest of the analysed specimens. However, as shown in Figure 10, this coefficient showed a clear decreasing tendency for all the studied mortars overall. It is interesting to note that at 45 hardening days, the majority of samples with red mud presented smaller $\mathrm{D}_{\mathrm{NTB}}$ coefficients in comparison with CEM I, with the exception of RM5 specimens, whose chloride migration coefficient was practically equal to that noted for CEM I samples, but lower than that corresponding to CEM II. Lastly, after 90 hardening days, the $\mathrm{D}_{\mathrm{NTB}}$ coefficient values for all the red mud mortars showed practically no differences with 
the $\mathrm{D}_{\mathrm{NTB}}$ value obtained for CEM I, although they were greater than the migration coefficient observed for CEM II samples.

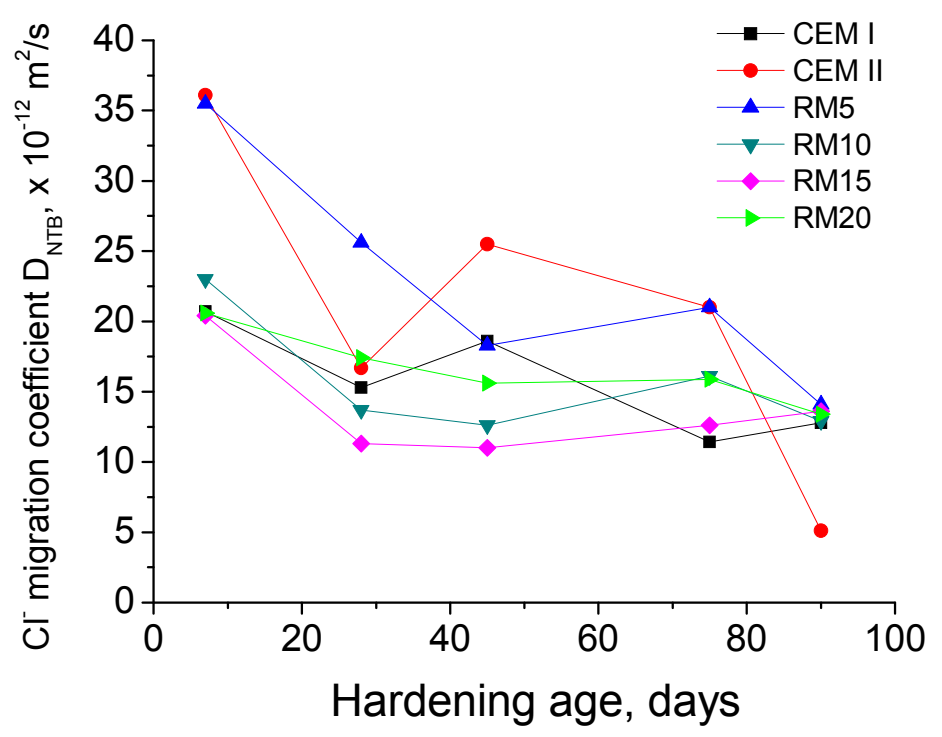

Figure 10. Results of the non-steady-state chloride migration coefficient for the studied mortars.

The results for the chloride migration coefficient are generally in agreement with the results of the microstructural study. The refinement of the pore network observed for the red mud mortars would mean that it would be more difficult for chlorides and other aggressive substances to ingress through these materials. It is very significant that despite replacing clinker with red mud, the value of the chloride migration coefficient had similar values for all the samples tested after 90 days. The cement that contained fly ash gave lower values for the migration coefficient, which would mean that it would be more resistant to chloride ingress [54,55], which can be partly attributed to the high chloride binding capacity of fly ash [56]. Despite reports that red mud also has a slight chloride binding capacity [23,27], it seems that this addition is not as efficient as fly ash. However, it provides the same behaviour related to chloride ingress resistance than the ordinary Portland cement, at least in the short-term, with an added value from an environmental point of view produced by the reutilization of a pollutant. Regarding the environmental benefits of using cement-based materials with red mud, the environmental assessment performed by Nikbin et al. [31] showed that when red mud content increases from $0 \%$ to $25 \%, \mathrm{CO}_{2}$-equivalent, as a measure of global warming potential, decreases from $556.8 \mathrm{Kg} \mathrm{m}^{-3}$ to $409.9 \mathrm{Kg} \mathrm{m}^{-3}$, implying that cement-based material sustainability increases with an increase of red mud content. Furthermore, those authors [31] also pointed out that with an increase in red mud content from $0 \%$ to $25 \%$, the reduction in the quantities of $\mathrm{CO}, \mathrm{NO}, \mathrm{Pb}_{\text {and }} \mathrm{SO}_{2}$ is about $32.5 \%$, $31.8 \%, 17.1 \%$ and $22.4 \%$ respectively. Finally, the relatively good behaviour of red mud regarding the resistance to chloride ingress observed here will be in line with other investigations [23-27], in which it has been shown that red mud has good performance in relation to the protection against corrosion of steel reinforcements embedded in concrete.

\subsection{Mechanical Strength Test}

The results of both compressive and flexural strengths are shown in Figures 11 and 12, respectively. As described in the experimental setup section, for checking the average effects on the mechanical properties of the addition of red mud, the abovementioned strengths were only studied in the RM10 and RM15 specimens, which were compared to those obtained for CEM I and CEM II mortars. 


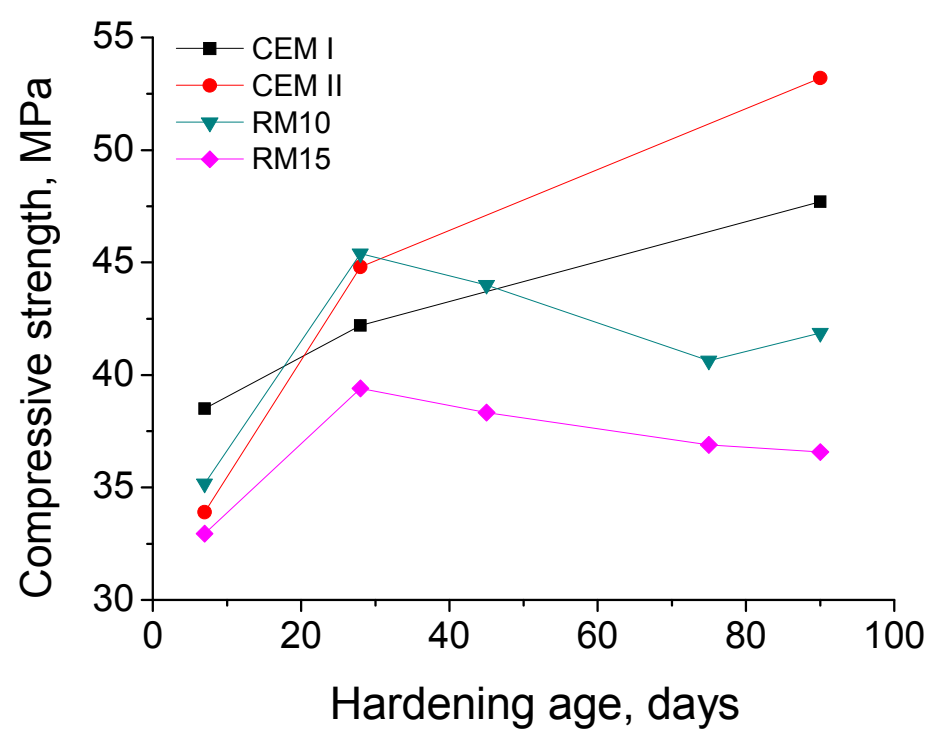

Figure 11. Results of compressive strength for CEM I, CEM II, RM10 and RM15 mortars.

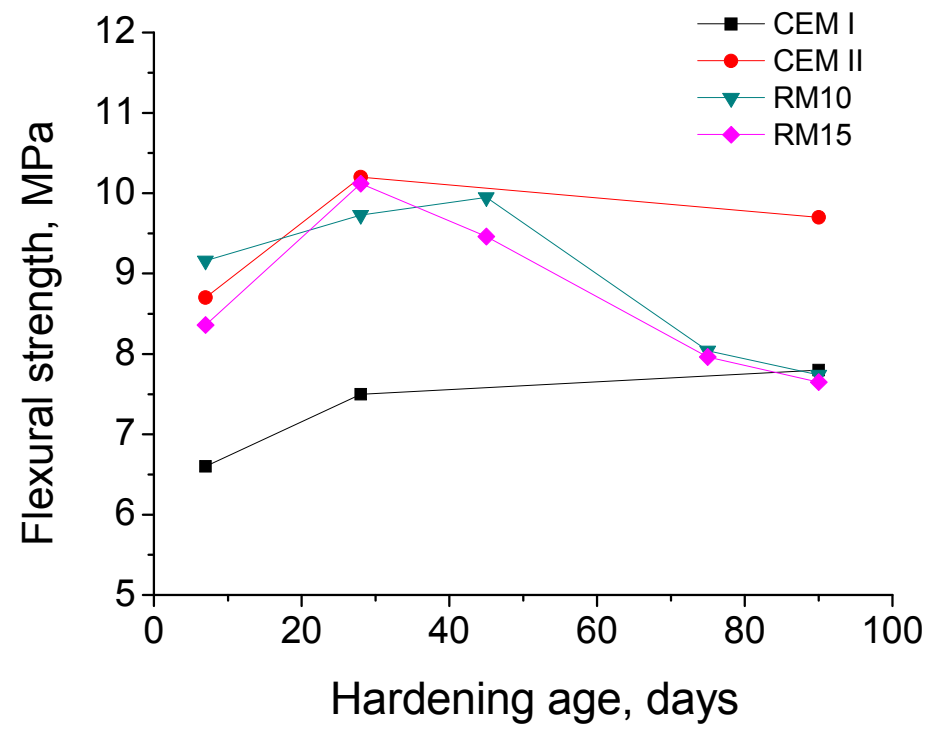

Figure 12. Results of flexural strength for CEM I, CEM II, RM10 and RM15 mortars.

The compressive strengths of red mud and CEM II mortars at seven days were similar (see Figure 11), although they were smaller than those observed for CEM I. At 28 days, the compressive strength noticeably increased for RM10 and CEM II mortars, showing the highest strengths of all the studied mortars at that hardening age. This rise was also observed for RM15 samples, although their compressive strength increase rate was lower. Nevertheless, since then, the compressive strength of red mud specimens started to decrease, while those for CEM I and CEM II mortars increased. After 90 hardening days, the highest compressive strength values corresponded to the CEM II mortars followed by CEM I, whereas the lowest values of this parameter were observed for the RM15 specimens.

In view of the compressive strength results, it is important to point out that the value of this parameter for RM10 mortars was approximately $45 \mathrm{MPa}$ at 28 days. This value is greater than the minimum value required by the Spanish and European standard UNE-EN 197-1 [39] for cements with strength class 42.5. However, due to the decrease of this parameter observed from that age, the RM10 mortars would not achieve this requirement at greater hardening times. On the other hand, the value of this strength for RM15 mortars was approximately $39 \mathrm{MPa}$ at 28 days, so they would not fulfil the previously explained requirement for strength class 42.5 cements. In spite of that, this RM15 
mortar could be classified as strength class 32.5 [39], because it far exceeded the minimum strength value required for that class at 28 days and greater hardening ages, despite a slight decrease of this parameter overtime.

Regarding the flexural strength (see Figure 12), the values of this parameter showed scarce differences up to 45 days for CEM II and red mud mortars, all of which were higher than those obtained for CEM I. Nevertheless, after 90 hardening days, the greatest flexural strength corresponded to CEM II specimens. At that age, this parameter was relatively similar for CEM I and red mud mortars.

In view of the mechanical properties results previously described, it can be pointed out that the addition of red mud produced the development of lower compressive strengths after 90 hardening days in the mortars, compared to those made with commercial cements without red mud. This result would be in line with other studies, in which red mud has been studied in cementitious materials. Senff et al. [57] reported lower mechanical strength in mortars when red mud level increases. Manfroi et al. [22] also observed a decrease of compressive strength when the red mud content in mortars is high, pointing out that the most appropriate substitution is up to $5 \%$ of red mud from a mechanical properties point of view. Finally, Nikbin et al. [31] studied red mud lightweight concretes and they concluded that by increasing the red mud content, the compressive strength decreased, providing the result that the 28 -day compressive strength of the specimen containing $25 \%$ red mud was about $29.5 \%$ lower than that of the reference concrete. However, as has been explained, the mortars with $10 \%$ and $15 \%$ of red mud content would achieve the requirements for cements with strength class 32.5 [39], and according to the results obtained, it is likely that for percentages of replacement of clinker by red mud lower than $10 \%$, the requirements for strength cement class 42.5 [39] would also be fulfilled. From the point of view of flexural strength, the red mud mortars seemed to have an adequate behaviour, especially compared to CEM I.

\section{Conclusions}

The main conclusions that can be obtained in view of the results already described and discussed can be summed up as follows:

- The addition of red mud produced a higher microstructure refinement of the mortars compared to those made with cements type I (ordinary Portland cement) and type II (Portland cement with fly ash), as shown by the higher number of pores with smaller diameters noted for red mud binders.

- The progressive pore refinement with hardening time observed for red mud mortars, as well as the reduction of the heat per gram corresponding to the peak of the decomposition of the portlandite in samples that were not carbonated, suggest that red mud can have pozzolanic activity.

- The impedance spectroscopy results agree with mercury intrusion porosimetry and differential scanning calorimetry results about the possible pozzolanic activity of red mud. The increase with time of resistance $R_{1}$ and capacitance $C_{2}$ for red mud mortars could indicate the creation of new solid phases as products of the pozzolanic reactions between the red mud particles and the clinker hydration products.

- After 90 hardening days, the non-steady state chloride migration coefficients obtained for all the red mud mortars showed practically no differences in comparison with those noted for CEM I. Therefore, the use of up to $20 \%$ red mud as clinker replacement is as efficient as ordinary Portland cement without additions regarding chloride ingress resistance, with the advantage of the contribution to sustainability.

- The addition of red mud produced lower compressive strengths after 90 hardening days in the mortars compared to those made with CEM I and CEM II. Nevertheless, the analysed mortars with the addition of red mud would achieve the requirements for strength cement class 32.5 according to Spanish and European standard UNE-EN 197-1 from 28 hardening days. 
Author Contributions: Some results included in this paper were obtained during the PhD thesis carried out by J.M.O. at the University of Alicante (Spain), under the supervision of I.S. and M.Á.C. J.M.O. wrote the paper. J.M.O., M.C., A.J.T.-A., T.R.-H. and I.S. performed the experiments. I.S. and M.Á.C. supervised the research work and revised the paper. All the authors contributed to conceive and design the experiments, and to analyse and discuss the results.

Funding: Part of this research was funded by the Spanish Agencia Estatal de Investigación (grant code BIA2016-80982-R) and by the European Regional Development Fund (grant code BIA2016-80982-R).

Acknowledgments: Authors would like to thank Cementos Portland Valderrivas, S.A. and Lafarge España, S.A. for providing the cements studied in this work. We also thank the company Alcoa (factory at San Cibrao, Spain) for providing the red mud.

Conflicts of Interest: The authors declare no conflict of interest.

\section{References}

1. Ayres, R.U.; John, H.; Bjorn, A. Utilisation of the wastes in the new millennium. MRSI Bull. 2001, 7, 477-480. [CrossRef]

2. Hind, A.R.; Bhargava, S.K.; Grocott, S.C. The surface chemistry of Bayer process solids: A review. Colloids Surf. A Physicochem. Eng. Asp. 1999, 146, 359-374. [CrossRef]

3. Tsakiridis, P.E.; Agatzini-Leonardou, S.; Oustadakis, P. Red mud addition in the raw meal for the production of Portland cement clinker. J. Hazard. Mater. 2004, 116, 103-110. [CrossRef] [PubMed]

4. Cengeloglu, Y.; Tor, A.; Ersoz, M.; Arslan, G. Removal of nitrate from aqueous solution by using red mud. Sep. Purif. Technol. 2006, 51, 374-378. [CrossRef]

5. Kalkan, E. Utilization of red mud as a stabilization material for the preparation of clay liners. Eng. Geol. 2006, 87, 220-229. [CrossRef]

6. Sushil, S.; Batra, V.S. Catalytic applications of red mud, an aluminium industry waste: A review. Appl. Catal. B Environ. 2008, 81, 64-77. [CrossRef]

7. Singh, M.; Upadhayay, S.N.; Prasad, P.M. Preparation of iron rich cements using red mud. Cem. Concr. Res. 1997, 27, 1037-1046. [CrossRef]

8. Pontikes, Y.; Rathossi, C.; Nikolopoulos, P.; Angelopoulos, G.N.; Jayaseelan, D.D.; Lee, W.E. Effect of firing temperature and atmosphere on sintering of ceramics made from Bayer process bauxite residue. Ceram. Int. 2009, 35, 401-407. [CrossRef]

9. Kavas, T. Use of boron waste as a fluxing agent in production of red mud brick. Build. Environ. 2006, 41, 1779-1783. [CrossRef]

10. Krivenko, P.; Kovalchuk, O.; Pasko, A.; Croymans, T.; Hult, M.; Lutter, G.; Vandevenne, N.; Schreurs, S.; Schroeyers, W. Development of alkali activated cements and concrete mixture design with high volumes of red mud. Constr. Build. Mater. 2017, 151, 819-826. [CrossRef]

11. Martín-Antón, M.; Negro, V.; del Campo, J.M.; López-Gutiérrez, J.-S.; Esteban, M.D. The gigantism of public works in China in the twenty-first century. Sustainability 2017, 9, 1581. [CrossRef]

12. Demirboğa, R. Thermal conductivity and compressive strength of concrete incorporation with mineral admixtures. Build. Environ. 2007, 42, 2467-2471. [CrossRef]

13. Glinicki, M.; Jóźwiak-Niedźwiedzka, D.; Gibas, K.; Dabrowski, M. Influence of Blended Cements with Calcareous Fly Ash on Chloride Ion Migration and Carbonation Resistance of Concrete for Durable Structures. Materials 2016, 9, 18. [CrossRef] [PubMed]

14. Williams, M.; Ortega, J.M.; Sánchez, I.; Cabeza, M.; Climent, M.A. Non-Destructive Study of the Microstructural Effects of Sodium and Magnesium Sulphate Attack on Mortars Containing Silica Fume Using Impedance Spectroscopy. Appl. Sci. 2017, 7, 648. [CrossRef]

15. Bijen, J. Benefits of slag and fly ash. Constr. Build. Mater. 1996, 10, 309-314. [CrossRef]

16. Bouikni, A.; Swamy, R.N.; Bali, A. Durability properties of concrete containing $50 \%$ and $65 \%$ slag. Constr. Build. Mater. 2009, 23, 2836-2845. [CrossRef]

17. Thomas, M.D.A.; Scott, A.; Bremner, T.; Bilodeau, A.; Day, D. Performance of slag concrete in marine environment. ACI Mater. J. 2008, 105, 628-634.

18. Ortega, J.M.; Pastor, J.L.; Albaladejo, A.; Sánchez, I.; Climent, M.A. Durability and compressive strength of blast furnace slag-based cement grout for special geotechnical applications. Mater. Constr. 2014, 64. [CrossRef] 
19. Coppola, L.; Bellezze, T.; Belli, A.; Bignozzi, M.C.; Bolzoni, F.; Brenna, A.; Cabrini, M.; Candamano, S.; Cappai, M.; Caputo, D.; et al. Binders alternative to Portland cement and waste management for sustainable construction-Part 2. J. Appl. Biomater. Funct. Mater. 2018, 16, 207-221. [CrossRef] [PubMed]

20. Coppola, L.; Bellezze, T.; Belli, A.; Bignozzi, M.C.; Bolzoni, F.; Brenna, A.; Cabrini, M.; Candamano, S.; Cappai, M.; Caputo, D.; et al. Binders alternative to Portland cement and waste management for sustainable construction-Part 1. J. Appl. Biomater. Funct. Mater. 2018, 16, 186-202. [CrossRef] [PubMed]

21. Liu, X.; Zhang, N.; Sun, H.; Zhang, J.; Li, L. Structural investigation relating to the cementitious activity of bauxite residue-Red mud. Cem. Concr. Res. 2011, 41, 847-853. [CrossRef]

22. Manfroi, E.P.; Cheriaf, M.; Rocha, J.C. Microstructure, mineralogy and environmental evaluation of cementitious composites produced with red mud waste. Constr. Build. Mater. 2014, 67, 29-36. [CrossRef]

23. Ribeiro, D.V.; Labrincha, J.A.; Morelli, M.R. Effect of the addition of red mud on the corrosion parameters of reinforced concrete. Cem. Concr. Res. 2012, 42, 124-133. [CrossRef]

24. Abreu, C.M.; Freire, L.; Nóvoa, X.R.; Pena, G.; Pérez, Y.M.C. Comparative study of the electrochemical behaviour of iron in alkaline media containing red mud and grey slurries. The effect of Al3+. Rev. Metal. 2009, 45, 5-13. [CrossRef]

25. Díaz, B.; Freire, L.; Merino, P.; Nóvoa, X.R.; Pérez, M.C. The effect of red mud in the electrochemical behaviour of carbon steel embedded in mortar. Rev. Metal. 2008, 44, 251-257. [CrossRef]

26. Collazo, A.; Cristóbal, M.J.; Nóvoa, X.R.; Pena, G.; Pérez, M.C. Electrochemical impedance spectroscopy as a tool for studying steel corrosion inhibition in simulated concrete environments-Red mud used as rebar corrosion inhibitor. J. ASTM Int. 2006, 3. [CrossRef]

27. Díaz, B.; Freire, L.; Nóvoa, X.R.; Pérez, M.C. Chloride and $\mathrm{CO}_{2}$ transport in cement paste containing red mud. Cem. Concr. Compos. 2015, 62, 178-186. [CrossRef]

28. Tang, W.C.; Wang, Z.; Liu, Y.; Cui, H.Z. Influence of red mud on fresh and hardened properties of self-compacting concrete. Constr. Build. Mater. 2018, 178, 288-300. [CrossRef]

29. Liu, R.-X.; Poon, C.-S. Effects of red mud on properties of self-compacting mortar. J. Clean. Prod. 2016, 135, 1170-1178. [CrossRef]

30. Lemougna, P.N.; Wang, K.-T.; Tang, Q.; Cui, X.-M. Study on the development of inorganic polymers from red mud and slag system: Application in mortar and lightweight materials. Constr. Build. Mater. 2017, 156, 486-495. [CrossRef]

31. Nikbin, I.M.; Aliaghazadeh, M.; Charkhtab, S.; Fathollahpour, A. Environmental impacts and mechanical properties of lightweight concrete containing bauxite residue (red mud). J. Clean. Prod. 2016, 172, 2683-2694. [CrossRef]

32. Baroghel-Bouny, V. Water vapour sorption experiments on hardened cementitious materials. Cem. Concr. Res. 2007, 37, 414-437. [CrossRef]

33. Ortega, J.M.; Ferrandiz, V.; Antón, C.; Climent, M.A.; Sánchez, I. Influence of curing conditions on the mechanical properties and durability of cement mortars. In Materials Characterisation IV: Computational Methods and Experiments; Mammoli, A.A., Brebbia, C.A., Eds.; WIT Press: Southampton, UK, 2009; pp. 381-392.

34. Ortega, J.M.; Sánchez, I.; Climent, M.A. Influence of environmental conditions on durability of slag cement mortars. In Proceedings of the 2nd International Conference on Sustainable Construction Materials and Technologies, Ancona, Italy, 28-30 June 2010; pp. 277-287.

35. Pastor, J.L.; Ortega, J.M.; Flor, M.; López, M.P.; Sánchez, I.; Climent, M.A. Microstructure and durability of fly ash cement grouts for micropiles. Constr. Build. Mater. 2016, 117, 47-57. [CrossRef]

36. Ortega, J.M.; Letelier, V.; Solas, C.; Moriconi, G.; Climent, M.Á.; Sánchez, I. Long-term effects of waste brick powder addition in the microstructure and service properties of mortars. Constr. Build. Mater. 2018, 182, 691-702. [CrossRef]

37. Ortega, J.M.; Letelier, V.; Miró, M.; Moriconi, G.; Ángel Climent, M.; Sánchez, I. Influence of waste glass powder addition on the pore structure and service properties of cement mortars. Sustainability 2018, 10, 842. [CrossRef]

38. Ortega, J.M.; Esteban, M.D.; Rodríguez, R.R.; Pastor, J.L.; Ibanco, F.J.; Sánchez, I.; Climent, M.A. Influence of Silica Fume Addition in the Long-Term Performance of Sustainable Cement Grouts for Micropiles Exposed to a Sulphate Aggressive Medium. Materials 2017, 10, 890. [CrossRef] [PubMed] 
39. Asociación Española de Normalización y Certificación (AENOR). UNE-EN 197-1:2011. Composición, Especificaciones y Criterios de Conformidad de Los Cementos Comunes; AENOR: Madrid, Spain, 2011; p. 30. (In Spanish)

40. Collazo, A.; Fernández, D.; Izquierdo, M.; Nóvoa, X.R.; Pérez, C. Evaluation of red mud as surface treatment for carbon steel prior painting. Prog. Org. Coat. 2005, 52, 351-358. [CrossRef]

41. Asociación Española de Normalización y Certificación (AENOR). UNE-EN 196-1:2005. Métodos de Ensayo de Cementos. Parte 1: Determinación de Resistencias Mecánicas; AENOR: Madrid, Spain, 2005; p. 36. (In Spanish)

42. Diamond, S. Aspects of concrete porosity revisited. Cem. Concr. Res. 1999, 29, 1181-1188. [CrossRef]

43. Diamond, S. Mercury porosimetry. Cem. Concr. Res. 2000, 30, 1517-1525. [CrossRef]

44. Cabeza, M.; Merino, P.; Miranda, A.; Nóvoa, X.R.; Sanchez, I. Impedance spectroscopy study of hardened Portland cement paste. Cem. Concr. Res. 2002, 32, 881-891. [CrossRef]

45. Sánchez, I.; Nóvoa, X.R.; de Vera, G.; Climent, M.A. Microstructural modifications in Portland cement concrete due to forced ionic migration tests. Study by impedance spectroscopy. Cem. Concr. Res. 2008, 38, 1015-1025. [CrossRef]

46. Ortega, J.M.; Esteban, M.D.; Rodríguez, R.R.; Pastor, J.L.; Sánchez, I. Microstructural Effects of Sulphate Attack in Sustainable Grouts for Micropiles. Materials 2016, 9, 905. [CrossRef] [PubMed]

47. Barsoukov, E.; Macdonald, J.R. Impedance Spectroscopy; Barsoukov, E., Macdonald, J.R., Eds.; John Wiley \& Sons, Inc.: Hoboken, NJ, USA, 2005; ISBN 9780471716242.

48. NT Build 492: Concrete, Mortar and Cement-Based Repair Materials: Chloride Migration Coefficient from Non-Steady-State Migration Experiments; Nordtest: Espoo, Finland, 1999; p. 8.

49. Zornoza, E.; Garcés, P.; Payá, J.; Climent, M.A. Improvement of the chloride ingress resistance of OPC mortars by using spent cracking catalyst. Cem. Concr. Res. 2009, 39, 126-139. [CrossRef]

50. Cabeza, M.; Keddam, M.; Nóvoa, X.R.; Sánchez, I.; Takenouti, H. Impedance spectroscopy to characterize the pore structure during the hardening process of Portland cement paste. Electrochim. Acta 2006, 51, 1831-1841. [CrossRef]

51. Ortega, J.M.; Sánchez, I.; Climent, M.A. Impedance spectroscopy study of the effect of environmental conditions on the microstructure development of sustainable fly ash cement mortars. Materials 2017, 10, 1130. [CrossRef] [PubMed]

52. Wang, A.; Zhang, C.; Sun, W. Fly ash effects. Cem. Concr. Res. 2004, 34, 2057-2060. [CrossRef]

53. Papadakis, V.G. Effect of fly ash on Portland cement systems. Cem. Concr. Res. 1999, 29, 1727-1736. [CrossRef]

54. Moffatt, E.G.; Thomas, M.D.A.; Fahim, A. Performance of high-volume fly ash concrete in marine environment. Cem. Concr. Res. 2017, 102, 127-135. [CrossRef]

55. Chalee, W.; Ausapanit, P.; Jaturapitakkul, C. Utilization of fly ash concrete in marine environment for long term design life analysis. Mater. Des. 2010, 31, 1242-1249. [CrossRef]

56. Leng, F.; Feng, N.; Lu, X. An experimental study on the properties of resistance to diffusion of chloride ions of fly ash and blast furnace slag concrete. Cem. Concr. Res. 2000, 30, 989-992. [CrossRef]

57. Senff, L.; Hotza, D.; Labrincha, J.A. Effect of red mud addition on the rheological behaviour and on hardened state characteristics of cement mortars. Constr. Build. Mater. 2011, 25, 163-170. [CrossRef]

(C) 2019 by the authors. Licensee MDPI, Basel, Switzerland. This article is an open access article distributed under the terms and conditions of the Creative Commons Attribution (CC BY) license (http://creativecommons.org/licenses/by/4.0/). 